Saint Louis University School of Law

Scholarship Commons

All Faculty Scholarship

2001

Dealing with Conflicts of Interest in Biomedical Research: Irb Oversight as the Next Best Solution to the Abolitionist Approach

Jesse Goldner

Follow this and additional works at: https://scholarship.law.slu.edu/faculty

Part of the Bioethics and Medical Ethics Commons, and the Law Commons 


\title{
Dealing with Conflicts of Interest in Biomedical Research: Irb Oversight as the Next Best Solution to the Abolitionist Approach
}

Journal of Law, Medicine \& Ethics, Vol. 28, No. 4, 2001

Jesse Goldner

Saint Louis University - School of Law

\begin{abstract}
$\underline{\text { Abstract }}$
The author details the conflicts of interest facing individual investigators and research institutions and describes the current mechanisms, primarily focused at the relationship between the investigator and the research institution, to regulate these conflicts. The author finds these mechanisms insufficient and believes that the best approach is not to regulate conflicts, but to abolish them. The author acknowledges, however, that there is a lack of political will in an abolitionist approach. He proposes, therefore, institutional review board oversight at the level of the relationship between researcher and individual subjects as the next best solution.
\end{abstract}

\section{Suggested Citation:}

Goldner, Jesse, Dealing with Conflicts of Interest in Biomedical Research: Irb Oversight as the Next Best Solution to the Abolitionist Approach. Journal of Law, Medicine \& Ethics, Vol. 28, No. 4, 2001. 